INTERSTITIAL LUNG DISEASE

\title{
Expression of glucocorticoid receptors $\alpha$ and $\beta$ in steroid sensitive and steroid insensitive interstitial lung diseases
}

\author{
L Pujols, A Xaubet, J Ramírez, J Mullol, J Roca-Ferrer, A Torrego, J A Cidlowski, C Picado
}

Thorax 2004;59:687-693. doi: 10.1136/thx.2003.013268

See end of article for authors' affiliations

Correspondence to Dr C Picado, Servei de Pneumologia, ICPCT, Hospital Clínic, Villarroel 170, 08036 Barcelona, Spain; cpicado@ub.edu

Received 17 July 2003 Accepted 16 April 2004
Background: Sensitivity to glucocorticoids may be related to the concentration of glucocorticoid receptors $\alpha(G R \alpha)$ and $\beta(G R \beta)$. A study was undertaken to assess $G R \alpha$ and GR $\beta$ expression in steroid insensitive interstitial lung disease (idiopathic pulmonary fibrosis (IPF)) and steroid sensitive interstitial lung diseases (sarcoidosis and cryptogenic organising pneumonia (COP)).

Methods: Lung tissue was obtained from control subjects and from patients with IPF, sarcoidosis, and COP. Pulmonary function tests were carried out at the time of lung biopsy and every 3 months. GR $\alpha$ and GR $\beta$ expression was evaluated by both competitive RT-PCR and immunohistochemistry. Data are presented as median and 25-75th percentile.

Results: GR $\alpha$ mRNA expression ( $10^{5}$ cDNA copies/ $\mu$ g total RNA) was higher in patients with steroid sensitive interstitial lung diseases $(10.0 ; 7.8-14.9 ; n=11)$ than in patients with IPF $(4.4 ; 3.2-6.6 ; n=19$; $\mathrm{p}<0.001$ ). GR $\beta$ expression was at least 1000 times lower than that of $G R \alpha$ and did not differ between the three groups. A negative correlation was found between GR $\alpha$ mRNA levels and the fibrotic pathology score of the tissue $(r=-0.484, p<0.01)$ and a positive correlation was found between $G R \alpha$ mRNA levels and improvement in forced vital capacity $(r=0.633 ; p<0.01)$ after treatment of patients with glucocorticoids. Immunoreactivity for GR protein was also higher in patients with sarcoidosis and COP than in those with IPF.

Conclusion: The variable response of some interstitial lung diseases to steroid treatment may be the result of differences in the expression of GR $\alpha$.
$\mathrm{T}$ he biological action of glucocorticoids is mediated through the activation of intracellular glucocorticoid receptors (GR). ${ }^{1}$ Human GR exists in at least two isoforms, GR $\alpha$ and GR $\beta$, originating from the same gene by alternative splicing of the GR primary transcript. ${ }^{2} \mathrm{GR} \alpha$ is the predominant isoform of the receptor; it has steroid binding activity and mediates either transactivation or transrepression of target genes. ${ }^{1}$ GR $\beta$ does not bind glucocorticoids and is unable to transactivate glucocorticoid responsive genes. ${ }^{23}$ Transfection studies have shown the dominant negative inhibition of GR $\beta$ on GR $\alpha$ activity, ${ }^{2}{ }^{4}$ although other studies have challenged this finding. ${ }^{36}$ The physiological function of GR $\beta$ is still unknown.

Glucocorticoids are used in the treatment of interstitial lung diseases such as idiopathic pulmonary fibrosis (IPF), sarcoidosis, and cryptogenic organising pneumonia (COP). However, the response to glucocorticoids differs widely from one disease to another and from patient to patient.

IPF is a progressive and usually fatal lung disease characterised by inflammation and fibroblast proliferation that results in irreversible distortion of the architecture of the lung. Although some patients initially respond to glucocorticoid treatment, the use of high doses of glucocorticoids does not improve the evolution of the disease. ${ }^{78}$ Cryptogenic organising pneumonia (COP) is a clinicopathological syndrome characterised by the presence of an inflammatory process with pathological evidence of connective tissue buds in the lumen of the distal airway and alveolar spaces, contrasting with minor interstitial fibrosis. In contrast to IPF, COP can usually be quickly resolved with glucocorticoids, although frequent relapses occur when treatment is tapered or discontinued. ${ }^{9}$ Sarcoidosis is a systemic granulomatous disease that primarily affects the lung. Treatment with oral glucocorticoids usually results in the relief of respiratory symptoms and improvement in chest radiographic findings and lung function tests. ${ }^{10}$

A direct correlation between sensitivity to glucocorticoids and the concentration of GR in cells has been reported. ${ }^{11}{ }^{12}$ Moreover, an overexpression of GR $\beta$ has been reported in steroid insensitive patients. ${ }^{13-17}$ We sought to determine whether the different responses to glucocorticoids in steroid sensitive and steroid insensitive interstitial lung diseases were related to changes in the pattern of expression of GR $\alpha$ and GR $\beta$ isoforms.

\section{METHODS \\ Subjects \\ Controls}

Lung tissue was obtained during pleurodesis for spontaneous pneumothorax from 12 subjects (seven men) of mean (SD) age 34 (3) years with no history of pulmonary disease and absence of respiratory infections in the previous 3 months. Five subjects were smokers (13 (2) pack-years) and seven were non-smokers.

\section{Interstitial lung diseases}

The approach to the diagnosis of interstitial lung diseases included clinical evaluation, radiological and functional assessment, transbronchial lung biopsy, and bronchoalveolar lavage (BAL). Open lung biopsy was only performed in cases in which the diagnosis was not established with these methods. Lung tissue was obtained during open lung biopsy

Abbreviations: COP, cryptogenic organising pneumonia; IPF, idiopathic pulmonary fibrosis; $\mathrm{GR}$, glucocorticoid receptor; $\mathrm{FEV}$, forced expiratory volume in 1 second; FVC, forced vital capacity; TLCO, carbon monoxide transfer factor 
for diagnosis of interstitial lung disease from 30 untreated patients.

\section{Idiopathic pulmonary fibrosis}

Lung tissue was obtained from 19 patients ( 12 men) of mean (SD) age 61 (3) years. Three were smokers (36 (2) packyears), 10 were non-smokers and six were ex-smokers. The diagnosis of IPF was made following the criteria established by the American Thoracic Society (ATS)/European Respiratory Society (ERS) statement. ${ }^{18}$ Surgical lung biopsy was performed to diagnose IPF because patients did not fulfil all the clinical criteria established by the ATS/ERS statement. The indications for surgical biopsy in the 19 patients with IPF included in the study were: presence of ground glass opacification on HRCT scan $(n=5)$, suspicion of associated lung cancer $(n=3)$, fibreoptic bronchoscopy not performed $(n=6)$, presence of lymphocytes $>15 \%$ or eosinophils $>20 \%$ in BAL fluid $(n=5)$. Histological analysis of the biopsy specimens showed that all patients had a usual interstitial pneumonia. None of the patients had other causes of interstitial lung disease such as drug toxicity, environmental exposure, or collagen vascular diseases.

\section{Sarcoidosis}

Lung tissue was obtained from five patients (two men) of mean (SD) age 55 (7) years. Four were non-smokers and one was an ex-smoker. All patients were in radiographic stage III. Surgical lung biopsy was indicated because transbronchial lung biopsy was negative and patients did not have any extrapulmonary involvement that made it possible to obtain histological confirmation of the disease.

\section{Cryptogenic organising pneumonia}

Lung tissue was obtained from six patients (three men) of mean (SD) age 56 (6) years. Four were non-smokers and two were ex-smokers. All the patients had clinical and radiological manifestations that suggested the diagnosis of COP. Surgical lung biopsy was indicated because transbronchial lung biopsy was negative.

The presence of dyspnoea was graded as follows: grade $0=$ no dyspnoea; grade $\mathrm{l}=$ breathlessness on hills or after two flights of stairs; grade 2 = breathlessness after one flight of stairs; grade $3=$ shortness of breath after walking on level ground; grade $4=$ shortness of breath at rest or on minimal exertion. Shortness of breath was present in 16 out of 19 patients with IPF ( six with grade 1 , eight with grade 2 , and two with grade 3 ). All the patients with sarcoidosis had shortness of breath at diagnosis (one with grade 1 , three with grade 2, and one with grade 3 ). Shortness of breath was present in all the patients with COP (one with grade 1, four with grade 2 , and one with grade 3 ).

Pulmonary function test findings at the time of the lung biopsy are shown in table 1. Clinical examination, chest radiography, and pulmonary function tests were carried out every 3 months or when there was any clinical evidence of disease progression. Progression of the disease was defined as follows: (1) increase in the degree of dyspnoea, and/or (2) fall in forced vital capacity (FVC) and/or lung carbon monoxide transfer factor (TLCO) $>15 \%$ with respect to the initial pulmonary function testing. The response to glucocorticoid treatment was defined as an improvement in FVC and/or TLCO of $>15 \%$ and/or an improvement in the degree of dyspnoea. Patients who did not show any improvement or deterioration were considered stable.

The study was approved by the ethics committee of our institution and informed consent was obtained from all subjects.

\section{Histopathological analysis}

Lung biopsies were analysed and graded for 11 pathological abnormalities according to the method described by Watters et al. ${ }^{19}$ Five were cellular abnormalities (alveolar desquamation, alveolar septal inflammation, inflammatory airway narrowing, obstructive pneumonitis, and lymphoid nodules) and six were fibrotic abnormalities (alveolar septal fibrosis, cystic changes, obliterative airway narrowing, smooth muscle hypertrophy, thickened pulmonary arterioles, and cuboidalisation of alveoli). Each abnormality was graded according to the extent and intensity of change present as absent, mild, moderate, or severe. An inflammatory score, a fibrotic score, and an index of overall pathological derangement of the lung structure (total pathological score) were calculated on the basis of the sum of the inflammatory and fibrotic scores.

\section{Immunohistochemistry}

Immunohistochemistry was performed in $4 \mu \mathrm{m}$ thick sections from tissue samples embedded in OCT (Tissue-Tek, Zoeterwoude, The Netherlands) using the Dako EnVision+ System kit, peroxidase (Dako Corporation, Carpinteria, CA, USA). Briefly, sections were fixed in cold acetone for 10 minutes, permeabilised in $0.5 \%$ saponin for 30 minutes, washed in phosphate buffered saline $(\mathrm{pH}=7.4)$ and incubated with either polyclonal anti-GR antibody 57 or polyclonal anti-GR $\beta$ antibody BShGR ${ }^{20}$ diluted in Dako's antibody diluent $(0.05 \mathrm{M}$ Tris- $\mathrm{HCl}, \mathrm{pH}$ 7.2-7.6, containing $1 \%$ bovine serum albumin) for 30 minutes. Endogenous peroxidase was inactivated with $0.03 \%$ hydrogen peroxide. After washing in phosphate buffered saline, sections were incubated with the peroxidase labelled polymer conjugated to goat anti-rabbit immunoglobulin for 30 minutes. Sections were then washed in phosphate buffered saline and the peroxidase staining was visualised with hydrogen peroxide and 3,3'-diaminobenzidine chromogen solution. Finally, sections were counterstained with Gill's haematoxylin, ethanol-dehydrated, and mounted in non-aqueous permanent mounting medium. Negative control of the immunohistochemical reaction was performed by replacing the primary antibody with antibody diluent.

The immunostained tissue sections were counted blindly by a pathologist using an Olympus microscope ( $\times 400$ magnification). The following cell types were counted in the immunohistochemical analysis: mononuclear cells

\begin{tabular}{|c|c|c|c|}
\hline & $\begin{array}{l}\text { IPF } \\
(n=19)\end{array}$ & $\begin{array}{l}\text { Sarcoidosis } \\
(n=5)\end{array}$ & $\begin{array}{l}\text { COP } \\
(n=6)\end{array}$ \\
\hline $\begin{array}{l}\text { FVC (\% predicted) } \\
\text { FVC (I) } \\
\text { FEV } / / F V C ~(\%) \\
\text { TLCO (\% predicted) } \\
\text { TLCO (ml/min/kPa) }\end{array}$ & $\begin{array}{l}66.6(3.8) \\
2.4(0.1) \\
0.8(0) \\
46.8(2.7) \\
1.5(0.1)\end{array}$ & $\begin{array}{l}61.6(3.7) \\
2.3(0.3) \\
0.7(0.1) \\
71.2(11.7) \\
2.2(0.3)\end{array}$ & $\begin{array}{l}58.0(8.0) \\
2.0(0.3) \\
0.9(0) \\
67.2(9.9) \\
2.1(0.5)\end{array}$ \\
\hline
\end{tabular}

Data are presented as mean (SE).

IPF, idiopathic pulmonary fibrosis; COP, cryptogenic organising pneumonia; FVC, forced vital capacity; FEV forced expiratory volume in 1 second; TLCO, carbon monoxide transfer factor. 
including lymphocytes, plasma cells and histiocytes, fibroblasts, epithelial cells, and alveolar macrophages. A minimum of 100 cells were counted for each cell type.

\section{Reverse transcriptase polymerase chain reaction (RT- PCR)}

Total RNA from lung tissue was reverse transcribed to complementary DNA (cDNA) using SuperScript II RNase $\mathrm{H}^{-}$reverse transcriptase. GR $\alpha$ and GR $\beta$ cDNAs were measured by competitive PCR in which known amounts of an exogenous DNA (competitor or internal standard) were coamplified in competition with the target cDNA in the same test tube, according to methods previously reported in detail elsewhere. ${ }^{2021}$

\section{Statistical analysis}

GR mRNA and protein data are presented as median and 2575th percentiles. GR $\alpha$ or GR $\beta$ mRNA is expressed as $10^{5}$ copies GR $\alpha$ cDNA or $10^{2}$ copies GR $\beta$ cDNA per $\mu$ g total RNA. Results from immunohistochemical analysis are expressed as percentage GR positive cells. The Kruskal-Wallis test was used to compare GR expression in the three groups and the Mann-Whitney U test was used for between group comparisons. The differences in age between controls and patients were compared using independent sample $t$ tests and the differences in the smoking status between controls and patients were compared using the Fisher test. Spearman rank correlation was used when analysing relationships between data. Statistical significance was set at $\mathrm{p}<0.05$.

\section{RESULTS}

\section{Response to glucocorticoid treatment}

\section{Idiopathic pulmonary fibrosis}

Seventeen of the 19 patients were treated with prednisone at a dose of $1 \mathrm{mg} / \mathrm{kg}$ daily for 1 month. The dose was then tapered by $10 \mathrm{mg}$ every 2 weeks to $20 \mathrm{mg}$ /day or every other day. Two patients did not receive any treatment. Contact was lost in five of the 17 glucocorticoid treated patients. Two patients died due to progression of the disease 12 months after the diagnosis. Another patient presented a significant increase in the degree of dyspnoea but he was unable to perform pulmonary function tests because he underwent a laryngectomy for cancer. Serial clinical evaluation and pulmonary function tests were available from nine patients for a follow up period of 24.7 (4.2) months (range 642 months). In six patients there was a deterioration in functional parameters (FVC, TLCO) and in the degree of dyspnoea, one remained stable, and two improved. On the whole, there was a deterioration in functional parameters despite glucocorticoid treatment. To determine more fully the changes in pulmonary function tests over the follow up period the changes in pulmonary function tests were divided by the duration of follow up for each patient (table 2).
According to the ATS/ERS consensus statement ${ }^{18}$ the recommended treatment for IPF is a combination of glucocorticoids and azathioprine or cyclophosphamide. However, as also mentioned in the statement, this treatment does not significantly change the outcome of the disease. The patients with IPF included in our study did not receive immunosuppressive drugs during the course of the study. Some of them were treated afterwards with immunosuppresive drugs, depending on the evolution of the disease. In order to determine the influence of glucocorticoids alone on $\mathrm{GR} \alpha$ expression we took special care to include patients treated with only glucocorticoids throughout the study.

\section{Sarcoidosis}

Patients with sarcoidosis $(n=5)$ were treated with prednisone at a dose of $40 \mathrm{mg} /$ day for 1 month. The dose was then tapered by $10 \mathrm{mg}$ every 2 weeks to $10 \mathrm{mg}$ /day or every other day. The follow up period was 17 (3) months (range 1024 months). Three patients showed an improvement in the degree of dyspnoea and in pulmonary function tests while two remained stable (table 2 ).

\section{Cryptogenic organising pneumonia}

Patients with COP $(n=6)$ were treated with prednisone at a dose of $1 \mathrm{mg} / \mathrm{kg}$ daily for $1 \mathrm{month}$. The dose was then tapered by $10 \mathrm{mg}$ every 2 weeks to $10 \mathrm{mg} /$ day or every other day. Serial pulmonary function tests and clinical evaluation were available in four patients for 20 (4.9) months (range 1232 months). All of them showed a significant improvement in functional parameters and the degree of dyspnoea (table 2). Another patient had a resolution of pulmonary infiltrates after glucocorticoid treatment. Contact was lost with one patient.

\section{Histopathological findings}

Inflammatory, fibrotic, and total scores were higher in patients with IPF and with steroid sensitive interstitial lung diseases (sarcoidosis and COP) than in control subjects (table 3). No significant differences were found in any of these scores between patients with IPF and those with steroid sensitive interstitial lung diseases.

\section{Expression of GR $\alpha$ and GRß mRNAs}

There was a higher expression of GR $\alpha$ mRNA $\left(\times 10^{5}\right.$ GR $\alpha$ cDNA copies/ $\mu$ g total RNA) in patients with steroid sensitive interstitial lung diseases $(10.0 ; 7.8-14.9 ; \mathrm{n}=11)$ than in patients with IPF $(4.4 ; 3.2-6.6 ; \mathrm{n}=19 ; \mathrm{p}<0.001)$. Although not statistically significant, there was a tendency to a higher expression $(p=0.06)$ of GR $\alpha$ mRNA in patients with steroid sensitive interstitial lung diseases than in control subjects (6.0; 4.7-13.3; $\mathrm{n}=12)$. GR $\alpha$ mRNA expression in patients with IPF was also not significantly different from that of control subjects $(p=0.07$, fig 1$)$. It is worth noting that the

\begin{tabular}{llll} 
Table 2 & Changes in pulmonary & function tests over the follow up period & \\
\hline & IPF & $\begin{array}{l}\text { Sarcoidosis } \\
(\mathbf{n}=5)\end{array}$ & $\begin{array}{l}\text { COP } \\
(\mathbf{n}=4)\end{array}$ \\
\hline Mean (range) follow up (months) & $24.7(6-42)$ & $17(10-24)$ & $20(12-32)$ \\
FVC (\% change from initial assessment) & $-10.6(4.2)$ & $12.2(6.6)$ & $30.2(10.1)$ \\
FVC (\% change/month) & $-0.4(0.4)$ & $0.8(0.5)$ & $1.5(0.3)$ \\
TLCO (\% change from initial assessment) & $-3.9(10.2) *$ & $19(12.2) \dagger$ & $54 \ddagger$ \\
TLCO (\% change/month) & $-0.2(1.2)^{*}$ & $1(0.8) \dagger$ & $4.5 \ddagger$ \\
\hline
\end{tabular}

Data are expressed as mean (SE).

Percentage change per month in FVC and TLCO were calculated by dividing the change in FVC and TLCO by the follow up period in months for each patient.

IPF, idiopathic pulmonary fibrosis; COP, cryptogenic organising pneumonia; FVC, forced vital capacity; TLCO, carbon monoxide transfer factor.

${ }^{*} \mathrm{n}=7 ;\lceil\mathrm{n}=3 ; \neq \mathrm{n}=1$. 
Table 3 Inflammatory, fibrotic, and total scores from healthy and pathological lungs

\begin{tabular}{lrllc}
\hline Lung type & $\mathrm{N}$ & Inflammatory score & Fibrotic score & \multicolumn{1}{l}{ Total score } \\
\hline Control & 9 & $2.0(0.5-3.0)$ & $1.0(0-4.0)$ & $2.0(1.0-7.0)$ \\
IPF & 18 & $7.0(4.7-10.5)^{* * *}$ & $8.5(5.7-14.0)^{* * *}$ & $15.5(10.7-23.5)^{* * *}$ \\
Sarcoidosis + COP & 11 & $7.0(4.0-8.0)^{* *}$ & $5.0(2.0-10.0)^{*}$ & $11.0(7.0-18.0)^{* *}$ \\
\hline
\end{tabular}

Results are expressed as median and $25-75$ th percentile.

$\mathrm{N}$, number of subjects; IPF, idiopathic pulmonary fibrosis; COP, cryptogenic organising pneumonia.

${ }^{*} \mathrm{p}<0.05,{ }^{* *} \mathrm{p}<0.01,{ }^{* * *} \mathrm{p}<0.001$ compared with controls (Mann-Whitney $U$ test).

control group was younger $(\mathrm{p}<0.001)$ and had many more smokers $(p<0.05)$ than the patient group. However, no correlation was found between GR $\alpha$ mRNA expression levels and age $(r=-0.018 ; \mathrm{p}=0.910 ; \mathrm{n}=42)$ or smoking status $(\mathrm{p}=0.604 ; \mathrm{n}=42)$. In all the lung tissues analysed the expression of GR $\beta$ mRNA was at least 1000 times lower than that of GR $\alpha$. In addition, no significant differences in GR $\beta$ mRNA expression $\left(\times 10^{2}\right.$ GR $\beta$ cDNA copies/ $\mu$ g total RNA) were found between patients with steroid sensitive interstitial lung diseases $(1.0 ; 0.3-1.7 ; \mathrm{n}=11)$ and either patients with IPF $(0.8 ; 0.2-1.3 ; \mathrm{n}=19)$ or control subjects $(0.8 ; 0.2-$ $3.2 ; \mathrm{n}=12$ ). There was no correlation between GR $\beta$ mRNA expression levels and age $(r=-0.218 ; \mathrm{p}=0.165 ; \mathrm{n}=42)$ or smoking status $(\mathrm{p}=0.320 ; \mathrm{n}=42)$.

No correlation was found between GR $\alpha$ mRNA levels and the tissue inflammatory score, and a negative correlation was found between GR $\alpha$ mRNA levels and the tissue fibrotic score $(r=-0.484 ; \mathrm{p}<0.01)$. A positive correlation was also found between GR $\alpha$ mRNA levels and changes in FVC $(r=0.633$; $\mathrm{p}<0.01 ; \mathrm{n}=18$ ) after treatment of patients with glucocorticoids in the follow up study (fig 2). The correlation between GR $\alpha$ mRNA levels and changes in TLCO was not statistically different $(r=0.545 ; \mathrm{p}=0.083 ; \mathrm{n}=11)$.

\section{Immunohistochemistry of GR $\alpha$ and $G R \beta$}

Because of limitations in tissue availability, immunohistochemistry could not be performed in all subjects. Immunohistochemistry was carried out in eight control lung tissues, 12 IPF tissues, and six sarcoidosis + COP tissues. Positive staining for GR was observed in mononuclear cells (lymphocytes, histiocytes and plasma cells), fibroblasts,

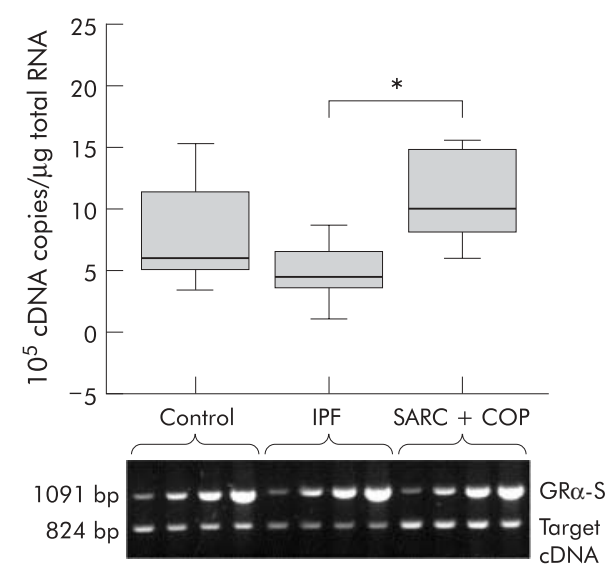

Figure $1 G R \propto m R N A$ expression in lung specimens from control subjects, patients with idiopathic pulmonary fibrosis (IPF) and patients with sarcoidosis and cryptogenic organising pneumonia (SARC + COP). Box plots show the 25th, 50th (median) and 75th percentile values. Whiskers show the minimum and maximum values. Also shown is a representative gel of GR $\alpha$ PCR. GR $\alpha$-S and target cDNA refer to amplification of GR $\alpha$ internal standard (1091 bp) and GR $\alpha$ target CDNA (824 bp), respectively; * $p<0.001$ (Mann-Whitney $U$ test).

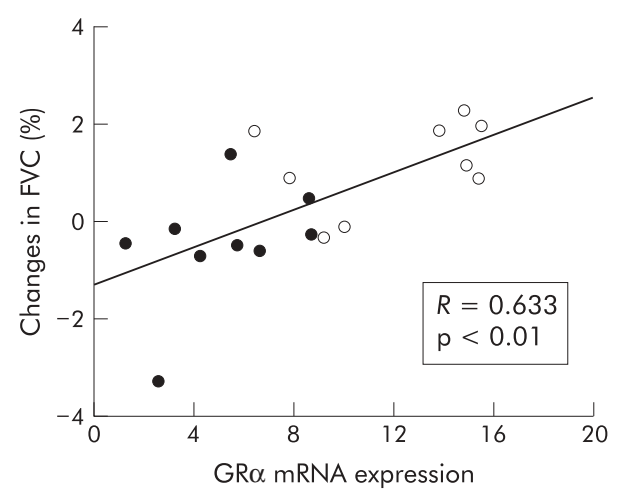

Figure 2 Correlation analysis (Spearman's correlation) between GR $\alpha$ mRNA levels and changes in FVC after glucocorticoid treatment in the follow up study. Solid circles are patients with IPF and open circles are patients with sarcoidosis and cryptogenic organising pneumonia (COP).

epithelial cells, and alveolar macrophages. With the exception of alveolar macrophages, the positive immunostaining for all cell types disappeared after incubation of tissue sections with antibody 57 preabsorbed with the peptide antigen (fig 3). The positive immunostaining observed in alveolar macrophages was therefore considered non-GR specific. In both control and pathological lungs the abundance or GR positive staining was mononuclear cells $>$ fibroblasts $>$ epithelial cells (fig 4). Interestingly, patients with steroid sensitive interstitial lung diseases showed higher immunoreactivity for each of these cell types than patients with IPF, which was significant for total cells (the sum of mononuclear cells, fibroblasts and epithelial cells; $\mathrm{p}<0.05$, figs 4 and 5 ). No correlation was found between total cell GR immunoreactivity and age $(r=-0.204 ; \quad \mathrm{p}=0.318 ; \mathrm{n}=26) \quad$ or smoking status $(\mathrm{p}=0.334 ; \mathrm{n}=26)$.

Low immunoreactivity for GR $\beta$ was observed in all tissues regardless of the tissue type, with occasional positive staining in mononuclear cells, fibroblasts, and epithelial cells from bronchioles.

\section{DISCUSSION}

To test the hypothesis that the different responses of some interstitial lung diseases to steroid treatment might be due to differences in the regulation of the GR, we assessed the expression levels of both GR isoforms (GR $\alpha$ and GR $\beta$ ) in lung tissue from control subjects and patients suffering from steroid insensitive interstitial lung disease (IPF) and steroid sensitive interstitial lung diseases (sarcoidosis and COP). The main findings of our study are: (1) GR $\alpha$ mRNA and GR protein expression were higher in lung biopsy specimens obtained from patients with steroid sensitive interstitial lung diseases than in biopsy specimens from patients with IPF; (2) there was a direct correlation between the improvement in FVC and basal GR $\alpha$ mRNA expression levels; and (3) in all tissues examined GR $\beta$ mRNA expression was more than 

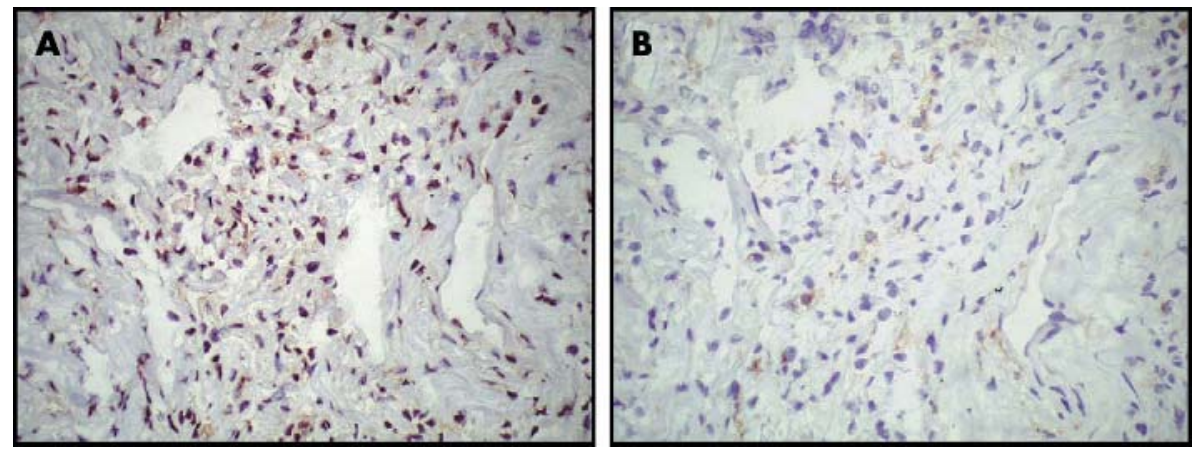

Figure 3 Specificity of polyclonal anti-GR antibody 57. (A) Lung tissue section stained with antibody 57 . Cell positivity is shown by the brown staining. (B) Consecutive lung tissue section stained with antibody 57 preabsorbed with the peptide antigen. Note the disappearance of GR immunostaining. Magnification $\times 400$.

1000 times lower than that of GR $\alpha$ and did not differ between control and pathological lungs.

One limitation of our study was the inability to include patients with non-specific interstitial pneumonia (NSIP). Since there is strong evidence that patients with NSIP have a good response to glucocorticoid treatment, the inclusion of patients with NSIP would probably have strengthened our results. During the study we diagnosed a few patients with NSIP but, unfortunately, we did not have enough tissue to perform the techniques included in this study.

In keeping with the numerous physiological effects of glucocorticoids in the human lung, GR $\alpha$ mRNA was detected in all lung specimens. ${ }^{1}$ GR $\alpha$ mRNA expression in patients with sarcoidosis and COP was significantly higher than in patients with IPF. A higher immunoreactivity for GR protein was also found in the sarcoidosis + COP lung tissues compared with that of IPF. These differences could be ascribed to the differential cellular composition found in these tissues. Accordingly, the negative correlation found between the fibrotic score of the tissue and basal GR $\alpha$ mRNA levels suggests that the lower GR $\alpha$ expression in patients with IPF may be partly explained by the fibrotic process of the tissue. In line with this, immunohistochemical analysis showed that fibroblasts were less immunoreactive for GR than mononuclear cells. In fact, in both control and pathological lungs the highest GR immunoreactivity was shown in mononuclear cells, followed by fibroblasts and epithelial cells. However, it is worth noting that all GR positive cell types within the sarcoidosis + COP tissues, particularly the mononuclear cells, had higher immunoreactivity than in the IPF tissues. For

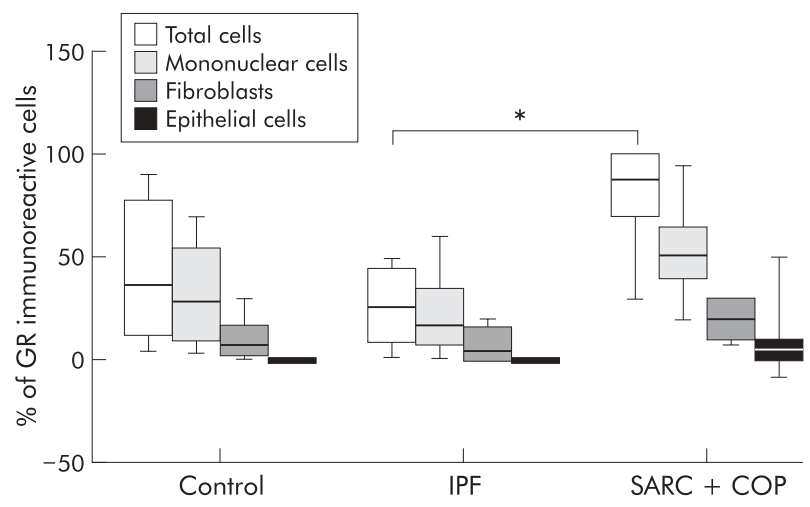

Figure 4 Percentage of GR positive cells in control, IPF, and sarcoidosis and cryptogenic organising pneumonia (SARC + COP) lung tissues. Total cells correspond to the sum of mononuclear cells, fibroblasts, and epithelial cells. ${ }^{*} p<0.05$ (Mann-Whitney $U$ test). instance, we found that $50 \%$ of the mononuclear cells were GR positive in the steroid sensitive diseases whereas only $17 \%$ of these cells were GR positive in patients with IPF. These findings indicate that the differences in GR $\alpha$ expression between steroid sensitive and steroid insensitive insterstitial lung diseases are not only due to differences in the cell composition of the tissue. We could therefore speculate that the expression of GR $\alpha$ may have been upregulated in the sarcoidosis + COP lung tissues by local tissue specific stimuli. In keeping with this, stimuli such as cyclic adenosine monophosphate, lipopolysaccharide, interleukin (IL)-1 $\beta$, or IL-6 have been shown to upregulate the expression of GR $\alpha$ in different cell lines. ${ }^{22-24} \mathrm{~A}$ number of proinflammatory molecules have been shown to be overexpressed in $\mathrm{COP}^{25}$ and sarcoidosis. ${ }^{26}$ Increased expression of Thl cytokines (interferon- $\gamma$, IL-2, IL-12, and IL-18) has been reported in sarcoidosis, whereas overexpression of Th2 cytokines (IL-4, IL-5, and IL-13) has been found in IPF lung tissue. ${ }^{27}$ However, whether any tissue specific cytokine, chemokine, or other stimuli released within the sarcoidosis + COP lung upregulates the expression of GR $\alpha$ is currently not known.

In spite of the limitation that functional studies during the follow up period were not available for all patients, we found a direct correlation between basal levels of GR $\alpha$ mRNA expression and the sensitivity of the patients to glucocorticoid treatment. These findings concur with previous studies reporting a direct correlation between hormonal sensitivity and cellular receptor levels. ${ }^{11} 12$

Since we have reported that fibroblasts-the predominant cell type in IPF lung-express lower amounts of GR $\alpha$ than mononuclear cells, we could speculate that their increase in numbers, in parallel with progression of the disease, would lead to a progressively reduced sensitivity to glucocorticoids. Regardless of the exact mechanism of glucocorticoid resistance in patients with IPF, our findings ultimately suggest that the poor response of patients with IPF to glucocorticoid treatment may be explained, at least in part, by the limited presence of GR $\alpha$.

The role of the GR in the response of interstitial lung diseases to glucocorticoids has barely been investigated. No previous studies have distinguished between GR $\alpha$ and $\mathrm{GR} \beta$ isoforms. Early studies using ${ }^{3} \mathrm{H}$-prednisolone binding reported a decreased number of GR in BAL cells from patients with IPF compared with control subjects. ${ }^{28}{ }^{29}$ In agreement with our results, Ozaki et al ${ }^{29}$ found a direct correlation between the number of ${ }^{3} \mathrm{H}$-prednisolone binding sites per cell in BAL cells from patients with IPF and the responsiveness of patients to glucocorticoids.

Three studies have assessed GR expression in patients with sarcoidosis and healthy subjects. Anderson et $a l^{30}$ could not find any significant difference in GR mRNA expression in 

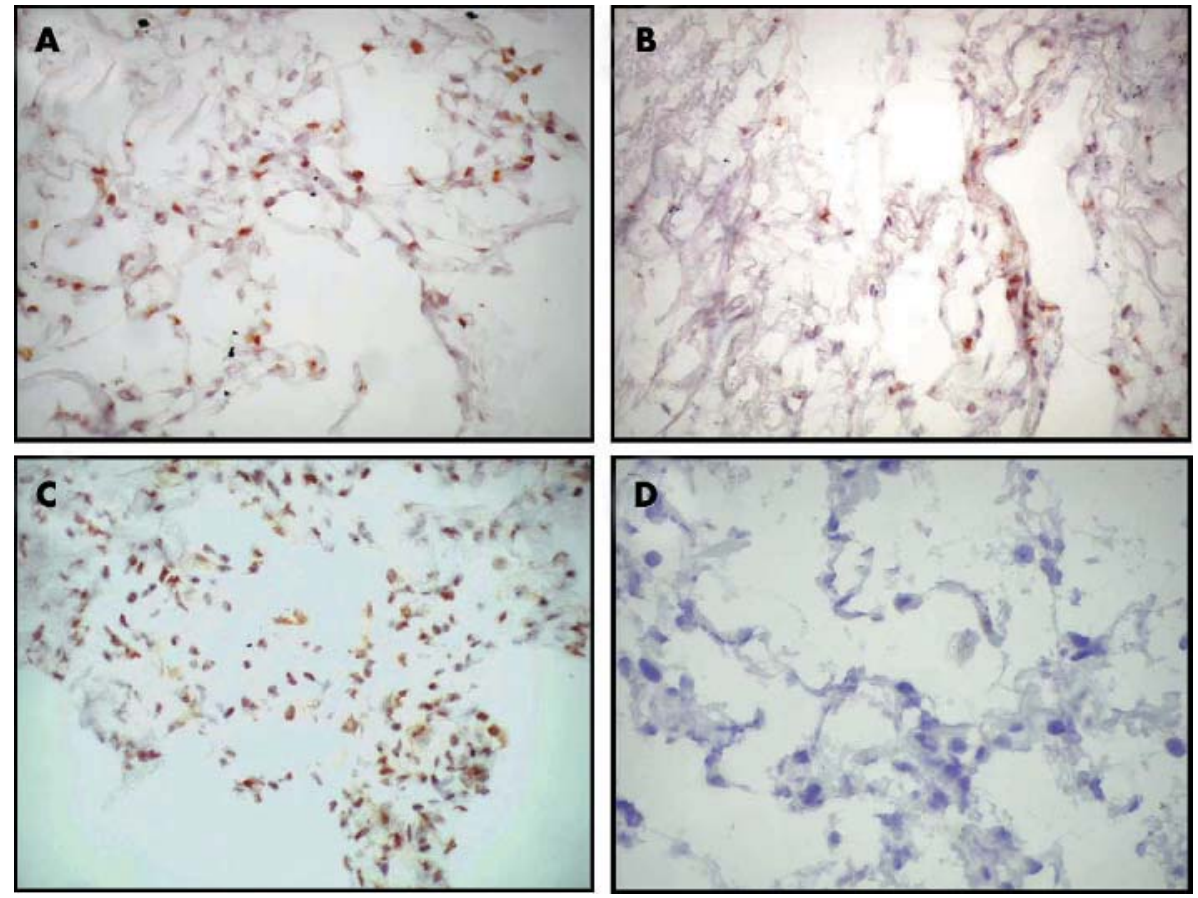

Figure 5 Representative image of GR immunohistochemistry in lung tissue from (A) a control subject, (B) a patient with IPF, (C) a patient with steroid sensitive interstitial lung disease, and (D) a negative control (one tissue section incubated with antibody diluent instead of primary antibody). Magnification $\times 400$.

pulmonary alveolar macrophages between patients with sarcoidosis and control subjects. In contrast, other investigators have reported higher GR levels in sarcoidosis lungs than in controls. ${ }^{31}$ Similarly, Sharma and colleagues ${ }^{32}$ found a higher GR content in BAL cells of patients with sarcoidosis compared with control subjects. To our knowledge, there are no previous reports analysing the expression of either the GR or its isoforms in patients with COP.

In all the analysed tissues the expression of GR $\beta$ mRNA was much lower than that of $G R \alpha$, a finding previously reported in various human tissues and cell lines. ${ }^{2} 162021$ In line with this, immunohistochemical analysis revealed low immunoreactivity for GR $\beta$ in both control and pathological tissues, with occasional positive staining in mononuclear cells, fibroblasts, and epithelial cells in the bronchioles. Increased GR $\beta$ expression has been reported in steroid insensitive patients with asthma, ${ }^{13-15}$ ulcerative colitis, ${ }^{16}$ and nasal polyposis. ${ }^{17}$ According to our results, differences in the regulation of GR $\beta$ expression cannot account for the variable response of interstitial lung diseases to glucocorticoids.

In summary, we report that the expression of GR $\alpha$ mRNA and GR protein was significantly higher in patients with sarcoidosis + COP than in those with IPF. A negative correlation was found between GR $\alpha$ mRNA levels and the tissue fibrotic score, and a positive correlation was found between GR $\alpha$ mRNA levels and the sensitivity of the patients to glucocorticoid treatment. IPF is a steroid insensitive condition while sarcoidosis and COP are diseases that usually respond to glucocorticoid treatment. Since the beneficial effects of glucocorticoids are mediated through activation of the GR $\alpha$ receptor, our results suggest that the different responses of some interstitial lung diseases to glucocorticoid therapy may be due to differences in the expression of the $\mathrm{GR} \alpha$ isoform. Although differences in the expression of GR $\beta$ have been reported in some steroid insensitive diseases, our study suggests that GR $\beta$ does not play a relevant role in determining hormone sensitivity in interstitial lung diseases.

\section{Authors' affiliations}

L Pujols, A Xaubet, J Ramírez, J Mullol, J Roca-Ferrer, A Torrego, C Picado, Institut d'Investigacions Biomèdiques August Pi i Sunyer (IDIBAPS), Barcelona, Spain

A Xaubet, A Torrego, C Picado, Servei de Pneumologia i Al.lèrgia Respiratòria, Institut Clínic de Pneumologia i Cirurgia Toràcica, Hospital Clínic, Departament de Medicina, Universitat de Barcelona, Barcelona, Spain

J Ramírez, Servei d'Anatomia Patològica, Hospital Clínic, Barcelona, Spain

J Mullol, Servei d'Otorinolaringologia, Hospital Clínic, Barcelona, Spain J A Cidlowski, Laboratory of Signal Transduction, National Institute of Environmental Health Sciences, National Institutes of Health, Research Triangle Park, NC, USA

This study was supported in part by grants from FIS 99-0133, SEPARFEPAR, Red RESPIRA (Fondo de Investigaciones Sanitarias, V-2003REDC 11 D-O), and CIRIT (2001 SGR 384).

\section{REFERENCES}

1 Reichardt HM, Schütz G. At the cutting edge. Glucocorticoid signalling: multiple variations of a common theme, Mol Cell Endocrinol 1998;146:1-6.

2 Oakley RH, Sar M, Cidlowski JA. The human glucocorticoid receptor beta isoform. Expression, biochemical properties, and putative function. J Biol Chem 1996;271:9550-9.

3 Hecht K, Carlstedt-Duke J, Stierna P, et al. Evidence that the beta-isoform of the human glucocorticoid receptor does not act as a physiologically significant repressor. J Biol Chem 1997;272:26659-64.

4 Bamberger CM, Bamberger A-M, de Castro $M$, et al. Glucocorticoid receptor beta, a potential endogenous inhibitor of glucocorticoid action in humans. J Clin Invest 1995;95:2435-41.

5 De Lange $\mathbf{P}$, Koper JW, Brinkmann AO, et al. Natural variants of the beta isoform of the human glucocorticoid receptor do not alter sensitivity to glucocorticoids. Mol Cell Endocrinol 1999;153:163-8.

6 Brogan IJ, Murray IA, Cerillo G, et al. Interaction of glucocorticoid receptor isoforms with transcription factors AP-1 and NF-kappaB: lack of effect of glucocorticoid receptor beta. Mol Cell Endocrinol 1999;157:95-104.

7 Flaherty KR, Toews GB, Lynch JP 3rd, et al. teroids in idiopathic pulmonary fibrosis: a prospective assessment of adverse reactions, response to therapy and survival. Am J Med 2001;110:278-82.

8 Selman M, King TE, Pardo A. Idiopathic pulmonary fibrosis: prevailing and evolving hypotheses about its pathogenesis and implications for therapy. Ann Intern Med 2001;134:136-51. 
9 Lazor R, Vandevenne A, Pelletier A, et al. Cryptogenic organising pneumonia: Characteristics of relapses in a series of 48 patients. Am J Respir Crit Care Med 2000;162:571-7

10 American Thoracic Society. Statement on sarcoidosis. Am J Respir Crit Care Med 1999:160:736-55.

11 Gehring U, Mugele K, Ulirich J. Cellular receptor levels and glucocorticoid responsiveness of lymphoma cells. Mol Cell Endocrinol 1984;36:107-13.

12 Vanderbilt JN, Miesfeld R, Maler BA, et al. Intracellular receptor concentration limits glucocorticoid-dependent enhancer activity. Mol Endocrinol 1987;1:68-74.

13 Leung DYM, Hamid Q, Vottero A, et al. Association of glucocorticoid insensitivity with increased expression of glucocorticoid receptor beta. J Exp Med 1997; 186:1567-74.

14 Hamid QA, Wenzel SE, Hauk PJ, et al. Increased glucocorticoid receptor beta in airway cells of glucocorticoid-insensitive asthma. Am J Respir Crit Care Med 1999; 159:1600-4.

15 Sousa AR, Lane SJ, Cidlowski JA, et al. Glucocorticoid resistance in asthma is associated with elevated in vivo expression of the glucocorticoid receptor beta-isoform. J Allergy Clin Immunol 2000;105:943-50.

16 Honda M, Orii F, Ayabe T, et al. Expression of glucocorticoid receptor beta in lymphocytes of patients with glucocorticoid-resistant ulcerative colitis. Gastroenterology 2000;1 18:859-66.

17 Hamilos DL, Leung DYM, Muro S, et al. GRbeta expression in nasal polyps inflammatory cells and its relationship to the anti-inflammatory effects of intranasal fluticasone. J Allergy Clin Immunol 2001;108:59-68.

18 American Thoracic Society. Idiopathic pulmonary fibrosis: diagnosis and treatment. International consensus statement. Am J Respir Crit Care Med 2000;161:646-64.

19 Watters LC, King TE, Schwarz MI, et al. A clinical, radiographic, and physiologic scoring system for the longitudinal assessment of patients with idiopathic pulmonary fibrosis. Am Rev Respir Dis 1986;133:97-103.

20 Pujols L, Mullol J, Roca-Ferrer J, et al. Expression of glucocorticoid receptor alpha- and beta-isoforms in human cells and tissues. Am J Physiol Cell Physiol 2002;283: C1324-31.
21 Pujols L, Mullol J, Pérez M, et al. Expression of the human glucocorticoid receptor alpha and beta isoforms in human respiratory epithelial cells and their regulation by dexamethasone. Am J Respir Cell Mol Biol 2001;24:49-57.

22 Dong Y, Aronsson M, Gustafsson J-A, et al. The mechanism of cAMP-induced glucocorticoid receptor expression. J Biol Chem 1989;264: 13679-83.

23 Verheggen MM, van Hal PT, Adriaansen-Soeting PW, et al. Modulation of glucocorticoid receptor expression in human bronchial epithelial cell lines by IL-1 beta, TNF-alpha and LPS. Eur Respir J 1996;9:2036-43.

24 Angeli A, Dovio A, Sartori ML, et al. Interactions between glucocorticoids and cytokines in the bone microenvironment. Ann NY Acad Sci 2002;966:97-107.

25 Cordier JF. Organising pneumonia. Thorax 2000;55:318-28.

26 Moller DR. Pulmonary fibrosis of sarcoidosis. New approaches, old ideas. Am J Respir Cell Mol Biol 2003;29:S37-41.

27 Noble PW. Idiopathic pulmonary fibrosis. New insights into classification and pathogenesis usher in a new era in therapeutic approaches. Am J Respir Cell Mol Biol 2003;29:S27-31.

28 Ozaki T, Yasuoka K, Nakayama T, et al. Glucocorticoid receptors in human alveolar macrophages and peripheral blood cells. Clin Exp Immunol 1982;47:505-11.

29 Ozaki T, Nakayama T, Ishimi H, et al. Glucocorticoid receptors in bronchoalveolar cells from patients with idiopathic pulmonary fibrosis. Am Rev Respir Dis 1982;126:968-71.

30 Anderson $\mathrm{O}$, Brönnegård M, Sonnenfeld T, et al. Glucocorticoid receptor mRNA expression in pulmonary alveolar macrophages in sarcoidosis. Chest 1991;99:1336-41.

31 De Carvalho CR, Brentani MM, Karialla RA, et al. Glucocorticoid receptor in active pulmonary sarcoidosis. Sarcoidosis 1990;7:93-5.

32 Sharma SH, Verma U, Pande JN, et al. Glucocorticoid receptors in bronchoalveolar lavage fluid in sarcoidosis. A preliminary report. Chest 1988;93:577-9.

\section{LUNG ALERT}

\section{Bronchial basal cell and epithelial repair}

$\Delta$ Hong KU, Reynolds SD, Watkins S, et al. Basal cells are a multipotent progenitor capable of renewing the bronchial epithelium. Am J Pathol 2004;164:577-88

U nderstanding the mechanisms of epithelial repair provides important insights into airway diseases such as asthma and COPD. The airway epithelial structure differs between the larger conducting airways and bronchioles in which, characteristically, basal cells are absent. In the distal airway Clara cells are absolutely necessary for epithelial repair but this is not so in tracheobronchial tissue. Here, the relative contribution to repair from Clara and basal cells is controversial.

This study explores the role of basal cells as a progenitor population in mouse bronchial epithelium ablated of Clara cells. Basal cells, identified by CK14 and GSI-B ${ }_{4}$ immunoreactivity, renewed bronchial epithelium after ganciclovir mediated depletion of Clara cells in CCtk transgenic mice and after naphthalene induced airway injury. Naphthalene is a toxin which specifically targets Clara cells. Following injury, basal cells were proliferative and adopted an intermediate morphology and molecular phenotype between true basal and Clara cells. In addition, the multipotential differentiation capacity of these cells was confirmed by an elegant lineage analysis in bitransgenic K14/RS mice in which basal, Clara, and ciliated cell populations were found to have arisen from CK14 expressing progenitors.

The authors have used multiple methodologies to establish the stem cell niche of epithelial basal cells in the mouse bronchus, providing evidence that they function as a transient amplifying cell in response to injury. If applicable to humans, this work implicates bronchial basal cells as contributory to the pathobiology of chronic lung diseases, and renders these cells as possible therapeutic targets. Bronchial basal cells are a worthy focus of further translational research.

D Faratian

Senior House Officer, Pathology Directorate, Royal Infirmary of Edinburgh, Edinburgh, UK ; dana.faratian@luht.scot.nhs.uk 